\title{
Inulin, oligofructose and mineral metabolism - experimental data and mechanism
}

\author{
Katharina E. Scholz-Ahrens* and J. Schrezenmeir \\ Institute of Physiology and Biochemistry of Nutrition, Federal Dairy Research Centre, Hermann-Weigmann-Str. 1, \\ 24103 Kiel, Germany
}

\begin{abstract}
Numerous investigations performed in animal models in the past 10 years have shown repeatedly that non-digestible oligosaccharides (NDO), such as inulin, oligofructose or transgalactooligosaccharides (TOS), stimulate mineral absorption, mainly calcium and magnesium. Longterm beneficial effects on bone health have been indicated by accumulation of bone mineral content in growing rats or prevention of bone loss in ovariectomized rats. However, bone mineral content or density are not necessarily associated with bone quality. In recent studies both oligofructose and calcium prevented loss of trabecular bone area induced by oestrogen deficiency, this, however, occurred at different trabecular shapes. The effects of NDO on mineral metabolism may be based on the enhancement of passive and active mineral transport across the intestinal epithelium, mediated by an increase in certain metabolites of the intestinal flora and a reduction of $\mathrm{pH}$. The possible impact of short-chain fatty acids, butyrate in particular, and of polyamines on the stimulation of mineral absorption capacity, and the interaction of oligofructose and antibiotics is discussed.
\end{abstract}

Prebiotics: Oligofructose: Mineral metabolism: Bone quality

\section{Introduction}

Dietary habits have changed in the past 50 years in westernized societies (Ernährungsbericht, 2000) including higher consumption of proteins, fats, sucrose, and sodium chloride, and lower intake of cereals and complex carbohydrates including nondigestible, bulking dietary fibres and nondigestible but fermentable carbohydrates (NDC) like inulin and oligofructose. Since wheat provides $70 \%$ of inulin and oligofructose in American diets (Moshfegh et al. 1999), it is assumed that the decreased intake of cereals lowered intake of NDC. Some 'modern' diseases, such as coronary heart disease, some cancers or osteoporosis are thought to be associated at least in part with these changes in dietary patterns (Fraser, 1999).

Nondigestible oligosaccharides (NDO), such as inulin, oligofructose, galacto-oligosaccharides (GOS), transgalacto-oligosaccharides (TOS), and soybean-oligosaccharides, or lactulose, but also certain resistant starches, sugar alcohols, fermentable fibre, and gums like guar gum hydrolysate (GGH), attracted attention in the past decade for their physiological and health promoting properties and thus for their potential to represent candidates for functional food ingredients (Fooks et al. 1999). It was observed that NDO had specific effects on gut physiology. Changes herein were reported to be associated with benefits for the host, such as improved gastrointestinal well-being associated with changes in the intestinal flora (van Loo et al. 1999). Although fibre substances like pectin or cellulose also pass through the small intestine undigested, there are several differences in physical properties like dispersibility, viscosity, and adsorbing capacity compared to inulin and oligofructose (Schneeman, 1999). These physical differences presumably explain the variation of physiological effects and why different NDO, fibre substances, and sugar alcohols affect mineral metabolism differently. Lactulose for example, increased calcium absorption from $26 \%$ to $37 \%$ in rats as did other sugars whose digestion was limited, like L- and D-arabinose, raffinose or sugar alcohols like xylitol (Brommage et al. 1993). In animal experiments it was shown that inulin and oligofructose improved mineral absorption (for review see Scholz-Ahrens et al. 2001) and that this was associated with the production of short-chain fatty acids (SCFA) and a lower $\mathrm{pH}$ in the

Abbreviations: $1,25[\mathrm{OH}]_{2} \mathrm{D}_{3}$, calcitriol; GGH, guar gum hydrolysate; GOS, galacto-oligosaccharides; NDC, nondigestible but fermentable carbohydrates; NDO, nondigestible oligosaccharides; ODC, ornithine decarboxylase; OVX, ovariectomy; SCFA, short-chain fatty acids; T.Ar, tissue area; Tb.Ar, trabecular area; Tb.Ar/T.Ar, trabecular area as percentage of tissue area; TBPf, trabecular bone pattern factor; Tb.Pm, trabecular perimeter; TOS, transgalacto-oligosaccharides.

Note: For the definition of the terms inulin and oligofructose please refer to the introductory paper (p. S139) and its footnote.

* Corresponding author: Dr K. E. Scholz-Ahrens, fax +49 431609 2472, email scholz-ahrens@bafm.de 
intestinal lumen. Compared to inulin, oligofructose stimulated calcium absorption slightly more effectively, while the effect on magnesium was similar (Delzenne et al. 1995). The production of total SCFA was not different but lactate was significantly higher following xylo-oligosaccharides and butyrate and was highest in oligofructose (derived both from inulin and sucrose) fed rats (Campbell et al. 1997). Moreover, the dose of NDO and the background dietary calcium used in different studies have their own impact on mineral absorption (Scholz-Ahrens et al. 2002).

To what extent observations on mineral balance allow assumptions on bone mineralization or bone quality requires information on the persistence of the stimulating effect of inulin and oligofrucose on mineral absorption, and on the relevance of improved calcium absorption with respect to bone mineralization, bone density and bone structure. These aspects are discussed in the following review.

\section{Mineral balance}

Most experiments on NDO lasted 3-4 weeks and were done in young growing rats (Table 1). In some cases animals were gastrectomized or they were magnesium or iron deficient. In some experiments mineral disappearance from the isolated or ligated caecum or colon was studied or the positive effect on mineral availability was demonstrated by prevention of anaemia, i.e. haematological parameters or by prevention of mineral deficiency. The doses used varied mostly between $2.5 \%$ and $10 \%$ in the diet. Minerals that were analysed included calcium, phosphorous, magnesium, iron, copper, and zinc. In young growing rats NDO exerted their most prominent effects on calcium and magnesium availability (Table 1). In aged ovariectomized rats $5 \%$ oligofructose added to a diet high in calcium $(1 \%)$ persistently reduced faecal calcium loss after 4 and 8 weeks. This effect became significant after 16 weeks (Fig. 1). Calcium retention was slightly but persistently higher after 4,8 , and 16 weeks. This effect failed significance because increased absorption was associated with increased urinary calcium. Higher urinary calcium however, reflected metabolic reaction on higher calcium influx from the gut and not calcium mobilization from the skeleton because bone mineral content was higher on oligofructose (Scholz-Ahrens et al. 2002). Iron absorption was less effectively stimulated compared to calcium or magnesium but more effectively than zinc (Table 1, Delzenne et al. 1995). Phosphorous absorption was not affected (Ohta et al. 1994) or was significantly lower on a diet with $1 \%$ calcium on oligofructose with $76 \cdot 3 \pm$ 2.82 [mean (pooled SEM)] compared to the group on maize starch with $87.8(2.82)$ after 4 weeks (ScholzAhrens et al. 2002). Since phosphorous excretion via urine was significantly lower as well, phosphorous retention was not affected after 4 and 8 weeks (not shown), and after 16 weeks (Fig. 2).

\section{Bone mineralization}

Few experiments were reported, in which the effect of 

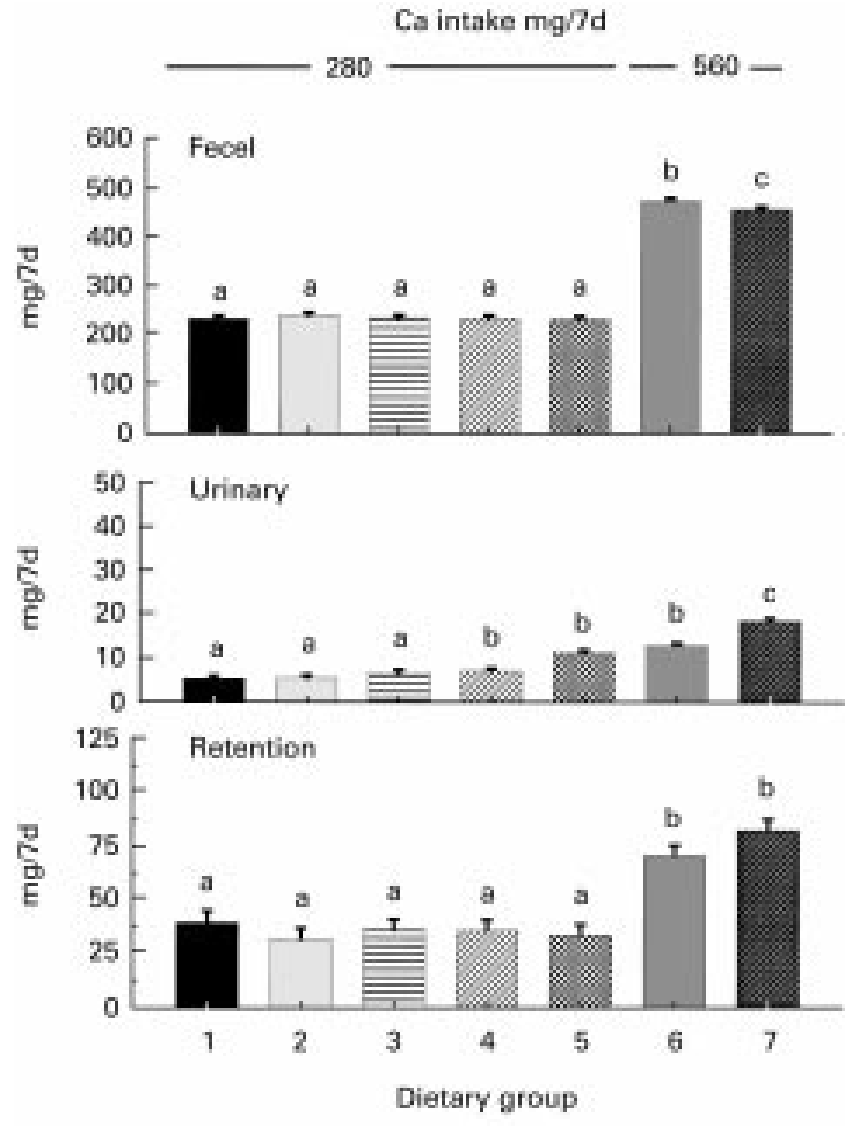

Fig. 1. Effect of oligofructose on 7-day calcium (Ca) balance in ovariectomized rats after 16 weeks on diets containing ( $\mathrm{g}$ calcium $/ \mathrm{kg}$ diet) / (g oligofructose $/ \mathrm{kg}$ diet) as follows: $\mathbf{\square}, 5 / 0 ; \square, 5 / 0$; 目, 5/25;, $5 / 50 ; \otimes, 5 / 100 ; \square, 10 / 0 ; \square, 10 / 50$. Animals in group 1 were sham operated, animals in groups $2-7$ were ovariectomized. Least square means and pooled SEM of MANOVA. a, b, c indicates significant differences between groups with $P$ of at least $<0.05$.

NDO on bone mineral content was investigated (Chonan et al. 1995; Ohta et al. 1998a; Scholz-Ahrens et al. 1998). Ovariectomy (OVX) in the adult or aged rat is an accepted method to simulate human postmenopausal state (Kimmel, 1996). In young (Chonan et al. 1995) and adult (Scholz-Ahrens et al. 2002) ovariectomized rats galactooligosaccharides and oligofructose effectively prevented loss of bone mineral content or density. The preventive effect in the femur was more prominent after 8 weeks than after 16 weeks while in the lumbar vertebra it occurred persistently over 16 weeks but with less magnitude. The addition of $5 \%$ oligofructose prevented bone loss significantly in the femur and lumbar vertebra in the presence of high dietary calcium $(1 \%)$ but not at $0.5 \%$ (Fig. 3). At $0.5 \%$ calcium $10 \%$ oligofructose was needed to significantly increase bone mineralization, and this was only observed in the femur (Scholz-Ahrens et al. 2002).

\section{Bone trabecular structure - bone quality}

In an experiment by our group, oligofructose was studied for its effect on bone trabecular structure in a long-term study in adult ovariectomized rats. Trabecular structure

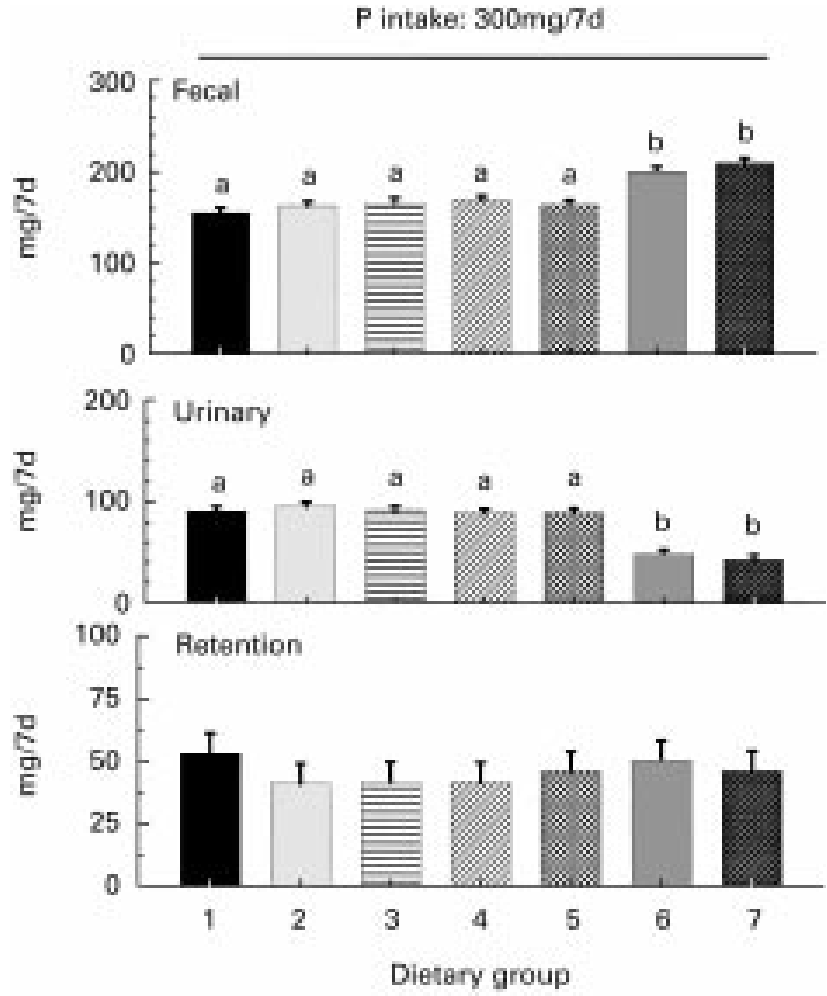

Fig. 2. Effect of oligofructose on 7-day phosphorous $(P)$ balance in ovariectomized rats after 16 weeks on diets containing (g calcium $/ \mathrm{kg}$ diet) / (g oligofructose $/ \mathrm{kg}$ diet) as follows: $\square, 5 / 0$; $\square, 5 / 0$; 目, 5/25; 四, 5/50;, $5 / 100 ; \square, 10 / 0 ; \square, 10 / 50$. Animals in group 1 were sham operated, animals in groups $2-7$ were ovariectomized. Least square means and pooled SEM of MANOVA. $a, b$, indicates significant differences between groups with $P$ of at least $<0.05$.

was assessed by computer-supported image analyses of contact microradiographs, a method described in detail elsewhere (Hein, 1997) and applied before to assess bioavailability of calcium from different sources (ScholzAhrens et al. 1997). Ovariectomy induced loss of tibia trabecular bone, particularly trabecular area (Tb.Ar/T.Ar), and trabecular perimeter (Tb.Pm) was reduced while tissue area (T.Ar) was not affected (Fig. 4a). To prevent ovariectomy-induced bone loss, rats were treated with higher dietary calcium $(1.0 \%$ v. $0.5 \%$, $)$ or by including $5 \%$ oligofructose in the diet or by combining both treatments for 8 and 16 weeks. Trabecular structure was affected differently by these treatments: Higher dietary calcium as well as including oligofructose preserved the trabecular area almost to the same extent (Fig. 4b). Higher dietary calcium, however, conserved fewer but thicker trabecules, while oligofructose conserved more trabecules compared to dietary calcium. This was also indicated by the higher values for trabecular perimeter after oligofructose, compared to the control group, 2 (Fig. 4b). The combined intervention, i.e. including $5 \%$ oligofructose into a diet containing $1 \%$ calcium, preserved a larger $\mathrm{Tb} . \mathrm{Ar} /$ $\mathrm{T}$.Ar at almost the same number but larger trabecular perimeter (Tb.Pm), thus indicating longer trabecules. Moreover, cortical thickness (C.Th) was significantly higher (Fig. 4c). Based on the bone structure analysis we demonstrated different bone quality following varying diets 
(Fig. 4). It may be speculated that a certain bone structure represents bone with more or less elasticity and break force resistance. From civil engineering it is known that a construction made of many thin beams is more stable than one made of a few thick ones. Therefore a certain trabecular architecture may reflect a surrogate for a lower fracture risk. Further data, however, are needed to define an architecture that is advantageous for bone health.

\section{Mechanism}

In the first place an enhancement of the passive calcium transport by NDO was favoured and postulated by several authors (Ohta et al. 1993; Levrat et al. 1991; Chonan et al. 1995), because the higher calcium solubility in the large intestine and its absorption was associated with a lower luminal $\mathrm{pH}$, and a selective stimulation of bacterial growth in vitro and in the intestinal lumen, mainly bifidobacteria and lactobacilli (Wang \& Gibson,1993; Rowland \& Tanaka, 1993; Gibson \& Roberfroid, 1995). At fermentation of inulin and oligofructose by the microflora the reduction of $\mathrm{pH}$ occurs as the result of stimulated production of lactic acid and short-chain fatty acids, mainly propionate and acetate, and at a lower level but at a higher rate, butyrate (Levrat et al. 1991). At lower $\mathrm{pH}$ more mineral is soluble in the gut lumen and thus is more readily absorbed from the gut mucosa cell (Ohta et al. 1995a). Apart from stimulating the passive calcium absorption indirectly by increasing its solubility via lowering the $\mathrm{pH}$ (Table 2), SCFA directly stimulated calcium disappearance across the colon in humans more effectively than a solution containing calcium $+\mathrm{NaCl}$, although the pH of the latter was lower (Trinidad et al. 1996). Calcium propionate stimulated calcium uptake more effectively than calcium acetate, although the $\mathrm{pH}$ of the infusion solutions were not different. It was discussed that a more rapid uptake of propionate compared to acetate was due to its greater lipid-solubility, which is associated with chain length (Trinidad et al. 1996).

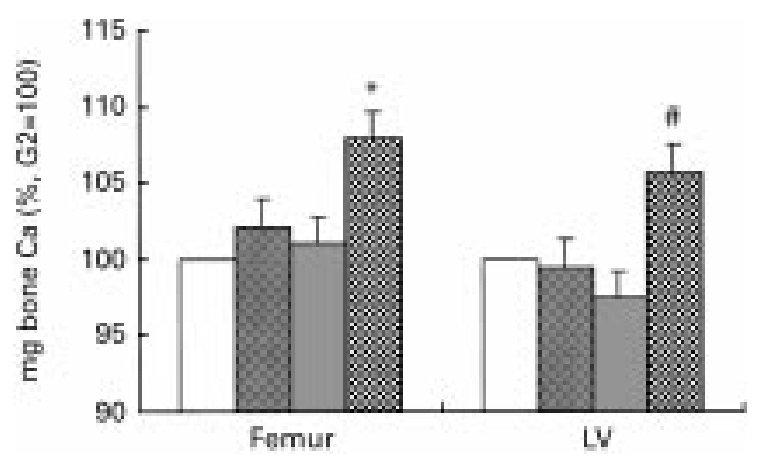

Fig. 3. Effect of oligofructose on calcium content (mg) of femur (left) and 1.+4. lumbar vertebra (LV, right) in ovariectomized rats after 16 wks on diets containing (g calcium $/ \mathrm{kg}$ diet) / (g oligofructose/ kg diet) as follows: $\square, 5 / 0$; $\otimes, 5 / 50 ; \square, 10 / 0$; 10/50. Least square means and pooled SEM of MANOVA. Values given are percentages of the mean of $5 / 0$. Significantly different ( $P$ of at least $<0.05)$ as follows: *different from $5 / 0$ and $10 / 0$, "different from $5 / 0$, $5 / 50$ and $10 / 0$.
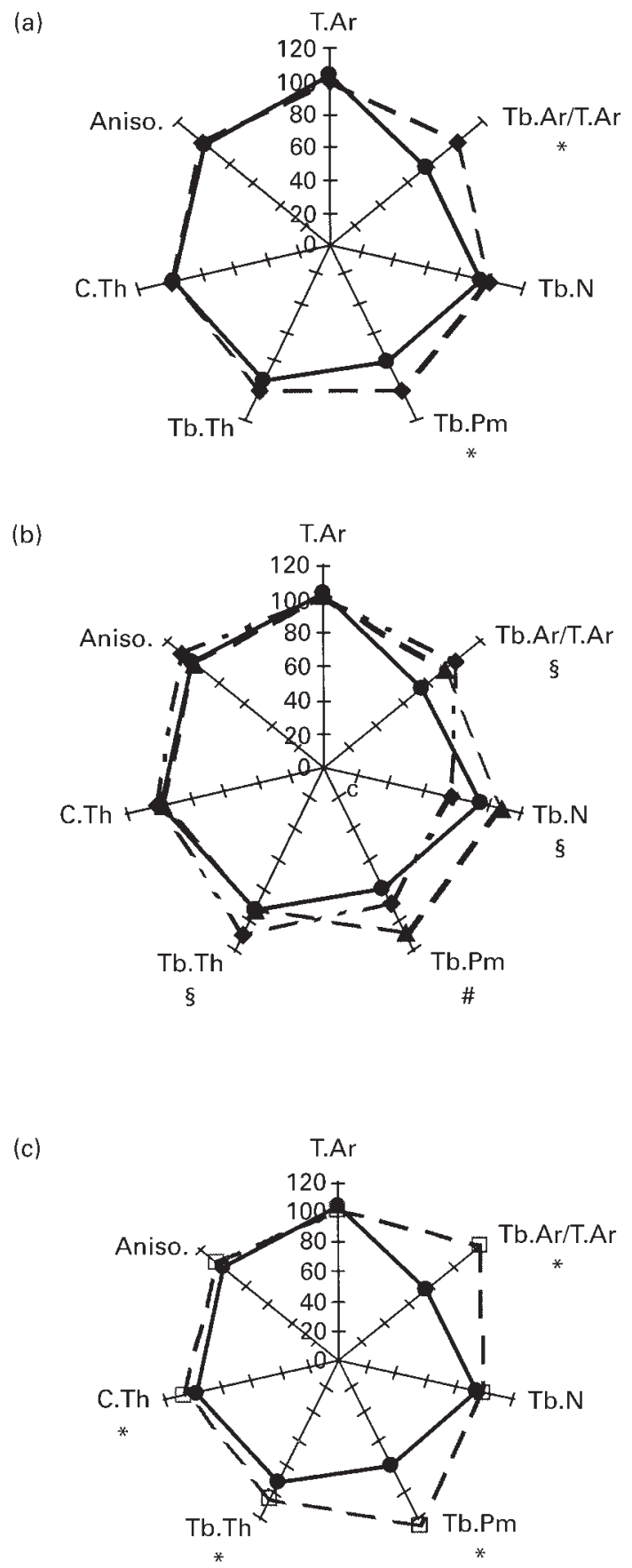

Fig. 4. Parameters of tibia trabecular structure following microradiography and computer-supported image analysis of the proximal tibia of adult ovariectomized rats on different diets. The figures indicate different bone quality depending on whether ovariectomyinduced bone loss (a) was prevented by oligofructose or calcium (b) or a combination of both (c). The experimental groups were fed semipurified diets with $5 \mathrm{~g} / \mathrm{kg}$ phosphorous and $5 \mathrm{~g} / \mathrm{kg}$ calcium without oligofructose ((a)——; group 1 and ——; group 2), $5 \mathrm{~g} / \mathrm{kg}$ calcium plus $50 \mathrm{~g}$ oligofructose $/ \mathrm{kg}$ (- ——; group 4) and $10 \mathrm{~g} / \mathrm{kg}$ calcium either without ((b) - - ; group 6) or with (—- -; group 7) $50 \mathrm{~g}$ oligofructose $/ \mathrm{kg}$. Group 1 was sham operated, groups 2, 4, 6, and 7 were ovariectomized. Least-squares means from MANOVA were given. Significant differences with $P$ at least $<0.05$ as follows: in (a) ${ }^{*} 1$ v. 2 ; in (b) ${ }^{\#} 4$ different from 2, ${ }^{\S} 6$ different from 2; in (c) ${ }^{*} 7$ v. 2 . 
Table 2. Aspects probably involved in the oligofructose-mediated stimulation of mineral absorption and bone mineralization

\begin{tabular}{|c|c|c|c|}
\hline Effect of oligofructose on & & Mediated via & Effect \\
\hline Passive transport & $\uparrow$ & $\begin{array}{l}\text { - SCFA production (acetate }>\text { propionate }>\text { butyrate })>\text { lactate } \\
\text { - Propionate }>\text { acetate }\end{array}$ & $\begin{array}{l}\downarrow \mathrm{pH}, \uparrow \text { mineral solubility } \\
\uparrow \text { exchange of cellular proton }(\mathrm{H}+) \\
\text { for luminal cation }(\mathrm{Ca}++)\end{array}$ \\
\hline & $\uparrow$ & $\begin{array}{l}\text { - Polyamines } \\
\text { - SCFA, mainly butyrate }\end{array}$ & $\begin{array}{l}\text { Growth and proliferation factor } \\
\text { Growth substrate for colonocytes }\end{array}$ \\
\hline Active transport & $\uparrow$ & $\begin{array}{l}\text { Butyrate } \\
\text { - Polyamines? }\end{array}$ & $\begin{array}{l}\uparrow \text { synthesis of CaBP } \\
\uparrow \text { synthesis of } 1,25(\mathrm{OH})_{2} \mathrm{D}_{3} \text { receptor? }\end{array}$ \\
\hline
\end{tabular}

Butyrate is given prominence to be a potent candidate for enhancing mineral absorption. Butyrate is a substrate for cell growth and proliferation (Lupton \& Kurtz, 1993). By increasing the floral butyrate production, fructo-oligosaccharides (FOS) might indirectly induce cell growth and growth of the gut's absorptive area, another way to contribute to the enhanced mineral absorption (Table 2). Moreover, FOS might be stimulative on the active calcium transport via butyrate production. Sodium butyrate increased the concentration of calbindin and of $1,25[\mathrm{OH}]_{2} \mathrm{D}_{3}$ receptor activity in chick primary culture cells (Anita \& Anthony, 1992). In rats that were fed a diet containing oligofructose (from sucrose), Ohta et al. $(1998 c)$ observed a higher expression of calcium binding protein (calbindin-D9k) in the large intestine, while that in the small intestine was decreased. Results reported by Le Blay et al. (1999) support the hypothesis that butyrate may have a marked impact on the effect of oligofructose. They observed that oligofructose reduced the $\mathrm{pH}$ in the caecal lumen after 2 weeks and this was mainly due to stimulated synthesis of lactate $(63.5 \mu \mathrm{mol} / \mathrm{g}$ wet contents at oligofructose and $3.6 \mu \mathrm{mol} / \mathrm{g}$ at basal) $>$ acetate $>$ butyrate. However, after 8 weeks, lactate production came down to concentration of basal diet, while acetate and butyrate were persistently stimulated over 27 weeks. Acetate was $69.5 \mu \mathrm{mol} / \mathrm{g}$ wet contents at oligofructose and $47.6 \mu \mathrm{mol} / \mathrm{g}$ at basal. Butyrate was $15.3 \mu \mathrm{mol} / \mathrm{g}$ wet contents at oligofructose and $4.7 \mu \mathrm{mol} / \mathrm{g}$ at basal. One might ask whether the low concentration of butyrate in relation to acetate, or lactate could have such a strong effect. Butyrate is very quickly taken up by the enterocytes and makes its detection difficult (Trinidad et al. 1996). This circumstance may explain the lack of coincidence of high luminal butyrate concentration and increased mineral uptake across the apical membrane. Inulin and oligofructose mainly stimulate growth of bifidobacteria, but these microbes produce only a little butyrate compared to other strains (Djouzi \& Andrieux, 1997). Therefore, data presently available do not support a causal relationship between stimulated mineral absorption by bifidobacteria via butyrate.

Polyamines, e.g. spermine, spermidine, and putrescine, are metabolites generated by several strains of microbes (Noack et al. 2000) as well as by higher organisms (Straub et al. 1995). Hence they occur almost ubiquitously. Polyamines are potent agents to stimulate proliferation of several organs including intestine (Buts et al. 1993; Lupton \& Kurtz, 1993; Löser et al. 1999) or cells in culture like osteoblasts (Klein \& Carlos, 1995). Thus they might at least in part be responsible for cell growth and enlargement of the resorptive surface and by this are further candidates for mineral absorption enhancers. Moreover it was proposed that polyamines have a metabolic effect. The low bone mass in subjects who consume excessive amounts of alcohol was explained by its inhibitory effect on osteoblast proliferation or on the activity of ornithine

Table 3. Effects of exogenous polyamines, oligofructose (as potential initiator of microbial polyamines synthesis), or antibiotics (for eradication of microbial polyamine production) on bone mineralization and intestinal weight and $\mathrm{pH}$ in adult ovariectomized rats

\begin{tabular}{|c|c|c|c|c|c|c|c|c|c|c|}
\hline & G1 & G2 & G3 & G4 & G5 & G6 & G7 & G8 & G9 & $P$-value \\
\hline $\begin{array}{l}\text { Femur weight } \\
\text { (mq) }\end{array}$ & $\begin{array}{l}494^{b} \\
(12)\end{array}$ & $\begin{array}{l}448^{a} \\
(12)\end{array}$ & $\begin{array}{l}457^{\mathrm{ab}} \\
(10)\end{array}$ & $\begin{array}{l}445^{a} \\
(12)\end{array}$ & $\begin{array}{l}479^{a b} \\
(9)\end{array}$ & $\begin{array}{l}500^{\mathrm{b}} \\
(10)\end{array}$ & $\begin{array}{l}486^{a b} \\
(7)\end{array}$ & $\begin{array}{l}476^{a b} \\
(10)\end{array}$ & $\begin{array}{l}489^{a b} \\
(9)\end{array}$ & 0.000 \\
\hline Femur ash & $240 \mathrm{bc}$ & $235 \mathrm{ab}$ & $233 a b$ & $232 \mathrm{ab}$ & $242 b c$ & $248 c$ & $228 a b$ & $223 a$ & $237 \mathrm{bc}$ & 0.001 \\
\hline (mg) & 3.3 & 4.0 & $3 \cdot 2$ & 4.5 & 3.6 & $2 \cdot 8$ & $3 \cdot 0$ & $2 \cdot 1$ & $3 \cdot 3$ & \\
\hline $\begin{array}{l}\text { Caecum weight } \\
\text { (g) }\end{array}$ & $\begin{array}{l}0.57^{a} \\
(0.02)\end{array}$ & $\begin{array}{l}0.55^{a} \\
(0.01)\end{array}$ & $\begin{array}{l}0.55^{a} \\
(0.01)\end{array}$ & $\begin{array}{l}0.55^{a} \\
(0.01)\end{array}$ & $\begin{array}{l}0.85^{b} \\
(0.03)\end{array}$ & $\begin{array}{l}1.31^{c} \\
(0.06)\end{array}$ & $\begin{array}{l}0.86^{b} \\
(0.05)\end{array}$ & $\begin{array}{l}0.83^{b} \\
(0.05)\end{array}$ & $\begin{array}{l}1.33^{c} \\
(0.09)\end{array}$ & 0.001 \\
\hline $\begin{array}{l}\text { Caecal contents } \\
\text { (g) }\end{array}$ & $\begin{array}{l}2 \cdot 37^{a} \\
(0.11)\end{array}$ & $\begin{array}{l}2.56^{a} \\
(0.01)\end{array}$ & $\begin{array}{l}2.50^{a} \\
(0.01)\end{array}$ & $\begin{array}{l}2.31^{a} \\
(0.11)\end{array}$ & $\begin{array}{l}5.58^{b} \\
(0.37)\end{array}$ & $\begin{array}{l}8.85^{c} \\
(0.57)\end{array}$ & $\begin{array}{l}4.97^{b} \\
(0.42)\end{array}$ & $\begin{array}{l}5.17^{b} \\
(0.53)\end{array}$ & $\begin{array}{l}9.95^{c} \\
(0.99)\end{array}$ & 0.001 \\
\hline Caecum pH & $\begin{array}{l}7.95^{6} \\
(0.03)\end{array}$ & $\begin{array}{l}7.98^{b c} \\
(0.08)\end{array}$ & $\begin{array}{l}8.15^{\mathrm{cd}} \\
(0.03)\end{array}$ & $\begin{array}{l}8.05^{b c} \\
(0.05)\end{array}$ & $\begin{array}{l}7.63^{a} \\
(0.04)\end{array}$ & $\begin{array}{l}7.62^{a} \\
(0.04)\end{array}$ & $\begin{array}{l}8.26^{d} \\
(0.04)\end{array}$ & $\begin{array}{l}8.29^{d} \\
(0.06)\end{array}$ & $\begin{array}{l}7.91 \mathrm{~b} \\
(0 \cdot 10)\end{array}$ & 0.001 \\
\hline Jejunum Ph & $\begin{array}{l}7.97^{\mathrm{ab}} \\
(0.07)\end{array}$ & $\begin{array}{l}7 \cdot 75^{a} \\
(0 \cdot 17)\end{array}$ & $\begin{array}{l}7.97^{\mathrm{ab}} \\
(0 \cdot 08)\end{array}$ & $\begin{array}{l}8 \cdot 13^{\mathrm{b}} \\
(0 \cdot 12)\end{array}$ & $\begin{array}{l}7.75^{a} \\
(0.03)\end{array}$ & $\begin{array}{l}7.73^{\mathrm{a}} \\
(0.06)\end{array}$ & $\begin{array}{l}8.02^{\mathrm{ab}} \\
(0.08)\end{array}$ & $\begin{array}{l}8.20^{\mathrm{b}} \\
(0.06)\end{array}$ & $\begin{array}{l}7.97^{a b} \\
(0.04)\end{array}$ & 0.001 \\
\hline
\end{tabular}

ANOVA, mean and (SEM), $N=12-14$, values within a row not sharing a superscript letter are significantly different with $P$ as indicated. The rats were fed semisynthetic diets for 16 weeks that contained $7 \mathrm{~g}$ calcium $/ \mathrm{kg}$ diet and either no additives (G1, G2; G1 = sham operated), or spermidine, spermine and putrescine in physiologic amounts (G3), high amounts (G4, equivalent to $10 \times$ polyamine content of G3), oligofructose (50 g/kg diet, G5), oligofructose + antibiotics (neomycin/metronidazol) (G6), antibiotics alone (G7), antibiotics + high amounts of polyamines (G8) or oligofructose + antibiotics + high amounts of polyamines (G9). 
decarboxylase (ODC), the rate-limiting enzyme for polyamine synthesis (Klein \& Carlos, 1995). Dietary inulin stimulated ODC activity (Rémésy et al. 1993), indicating increased polyamine synthesis by the intestinal microflora. Stimulated intestinal microbial polyamine production was also observed after feeding of guar gum or pectin, two highly fermentable dietary fibres (Noack et al. 1998). Since exogenous or microbial polyamines are readily taken up by enterocytes or can pass into the circulation (Bardócz et al. 1993), polyamines may also stimulate gene expression of calcium binding proteins in the gut.

When rats were fed oligofructose for 4 weeks, putrescine concentration was higher and spermidine concentration lower, while total polyamine concentration was unchanged in the caecal contents compared to a standard diet. In the caecal tissue putrescine, spermidine and total polyamine concentrations were increased with diets containing oligofructose (Delzenne et al. 2000). Higher polyamine concentrations were also observed in rats after feeding of pectin or guar gum (Noack et al. 1998).

In vitro studies have demonstrated that fusobacterium synthesised mainly putrescine and bacteroides mainly spermidine, while bifidobacterium did not synthesise any of the polyamines (Noack et al. 1998). This observation does not support a causal relation between oligofructose-stimulated mineral absorption and increased polyamine synthesis due to selective stimulation of growth of intestinal bifidobacteria.

To test whether the oligofructose-induced stimulation of mineral absorption is mediated by polyamines, a study with adult ovariectomized Fisher-344 rats was done by our group. The animals were fed semisynthetic diets for 16 weeks that contained $7 \mathrm{~g}$ calcium $/ \mathrm{kg}$ diet and either no additives (G1, G2; G1 = sham operated), or spermidine, spermine and putrescine in physiological amounts (G3), high amounts $(\mathrm{G} 4$, equivalent to $10 \times$ polyamine content of G3), oligofructose $(50 \mathrm{~g} / \mathrm{kg}$ diet, G5), oligofructose + antibiotics (neomycin/metronidazol) in order to eradicate the intestinal flora (G6), antibiotics alone (G7), antibiotics + high amounts of polyamines (G8) or oligofructose + antibiotics + high amounts of polyamines (G9). The hypothesis was that oligofructose would increase mineral availability to a more or less comparable degree than exogenous polyamines and that this effect may be diminished in the presence of antibiotics, which eradicate most polyamine producers. We observed a significant loss of femur weight following ovariectomy (Table 3). The highest femur ash was gained in the groups containing oligofructose, either alone (G5) or in combination with antibiotics (G6) or in combination with antibiotics + polyamines (G9). Exogenous polyamines slightly increased the $\mathrm{pH}$ of cecal contents and significantly of jejunal contents at the high dose. In contrast to diets containing oligofructose, especially in combination with antibiotics (G6), exogenous polyamines alone did not prevent loss of femur weight and femur ash (Table 3). Antibiotics alone almost prevented loss of femur weight, but not loss of femur ash, which was prevented when antibiotics were combined with oligofructose (G6, Fig. 5). Antibiotics increased caecum weight and weight of caecal contents in a comparable magnitude as oligofructose. However, antibiotics did not reduce the

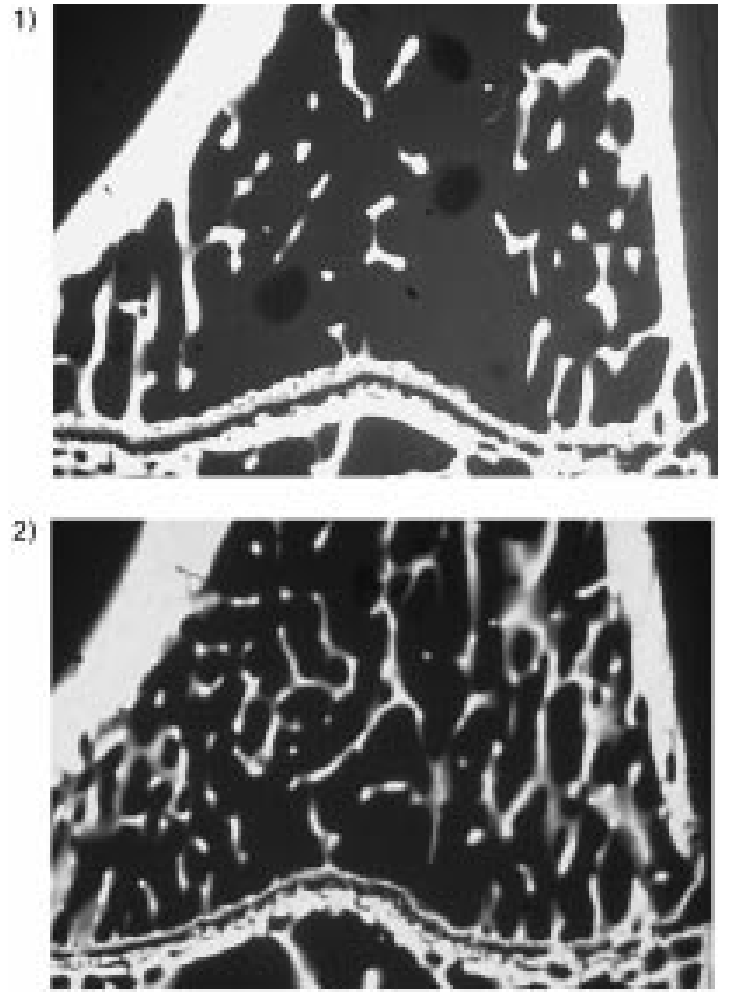

Fig. 5. Microradiograph of the proximal tibia of a 9-month old ovariectomized Fisher-344 rat after treatment with antibiotics (1) or after treatment with antibiotics in the presence of oligofructose (2).

$\mathrm{pH}$ in the caecal contents, in contrast to oligofructose, but rather increased it. Data of this experiment revealed that the femur ash, in contrast to femur weight, was highest correlated with $\mathrm{pH}$ of the caecal content and to a much less degree to the weight of the caecum or of the caecal contents (Table 4). Femur weight was highest correlated with caecal weight.

We conclude that the potential of oligofructose to prevent ovariectomy-induced loss of bone weight and bone mineral may not be mediated via polyamines, since exogenous polyamines were not protective, possibly because endogenous polyamine synthesis compensated for it. The bone-protecting effect of oligofructose in combination with a reduction of fecal flora was associated with a significant drop of caecal $\mathrm{pH}$. This indicates that oligofructose can prevent not only loss of bone mineral

Table 4. Pearson correlation coefficient $(r)$ of means of bone mineral and of caecal $\mathrm{pH}$, caecal weight and weight of caecal content in ovariectomized rats fed semisynthetic diets that contained physiological amounts of polyamines, high amounts of polyamines, oligofructose, anitibiotics, oligofructose + antibiotics, polyamines + antibiotics or oligofructose + antibiotics + polyamines to induce different femur ash

\begin{tabular}{|c|c|c|c|}
\hline Femur & $\mathrm{pH}$ & $\begin{array}{l}\text { Caecu } \\
\text { Content }(\mathrm{g})\end{array}$ & Organ weight (g) \\
\hline & \multicolumn{3}{|c|}{$r$} \\
\hline Bone weight (g) & -0.35 & 0.67 & 0.71 \\
\hline Ash weight $(\mathrm{q})$ & -0.94 & 0.37 & 0.39 \\
\hline Calcium (mg) & -0.88 & 0.37 & 0.40 \\
\hline
\end{tabular}


content but also the undesirable side effect of raising alkalinity in the large bowel following treatment with antibiotics.

\section{References}

Anita CM \& Anthony WN (1992) Effects of sodium butyrate on 1,25-dihydroxyvitamin D3 receptor activity in primary chick kidney cells. Molecular and Cellular Endocrinology 84, 99-107.

Baba S, Ohta A, Ohtsuki M, Takizawa T, Adachi T \& Hara H (1996) Fructooligosaccharides stimulate the absorption of magnesium from the hindgut in rats. Nutrition Research 16, 657-666.

Bardócz S, Grant G, Brown DS, Ralph A \& Pusztai A (1993) Polyamines in food-implications for growth and health. Journal of Nutritional Biochemistry 4, 66-71.

Bouhnik Y, Flourié B, D’Agay-Abensour L, Pochart P, Gramet G, Durand M \& Rambaud J-C (1997) Administration of transgalacto-oligosaccharides increases fecal bifidobacteria and modifies colonic fermentation metabolism in healthy humans. Journal of Nutrition 127, 444-448.

Brommage R, Binacua C, Antille S \& Carrié A-L (1993) Intestinal calcium absorption in rats is stimulated by dietary lactulose and other resistant sugars. Journal of Nutrition $\mathbf{1 2 3}$, 2186-2194.

Buts J-P, de Keyser N, Kolanowski J, Sokal E \& van Hoof F (1993) Maturation of villus and crypt cell functions in rats small intestine role of dietary polyamines. Digestive Diseases and Science 38, 1091-1098.

Campbell JM, Fahey GC Jr \& Wolf BW (1997) Selected indigestible oligosaccharides affect large bowel mass, cecal and fecal short-chain fatty acids, $\mathrm{pH}$ and microflora in rats. Journal of Nutrition 127, 130-136.

Chonan O, Matsumoto K \& Watanuki M (1995) Effect of galactooligosaccharides on calcium absorption and preventing bone loss in ovariectomized rats. Bioscience Biotechnology Biochemistry 59, 236-239.

Delzenne N, Aertssens J, Verplaetse H, Roccaro M \& Roberfroid M (1995) Effect of fermentable fructo-oligosaccharides on mineral, nitrogen and energy digestive balance in the rat. Life Science 57, 1579-1587.

Delzenne NM, Kok N, Deloyer P \& Dandrifosse G (2000) Dietary fructans modulate polyamine concentration in the cecum of rats. Journal of Nutrition 130, 2456-2460.

Djouzi Z \& Andrieux C (1997) Compared effects of three oligosaccharides on metabolism of intestinal microflora in rats inoculated with a human faecal flora. British Journal of Nutrition 78, 313-324.

Ernährungsbericht (2000) Ernährungssituation in Deutschland, pp. 17-58 [Deutsche Gesellschaft für Ernährung e.V., editor]. Frankfurt/Main.

Fooks LJ, Fuller R \& Gibson GR (1999) Prebiotics, probiotics and human gut microbiology. International Dairy Journal 9 , $53-61$.

Fraser GE (1999) Associations between diet and cancer, ischemic heart disease, and all-cause mortality in non-Hispanic white California seventh day adventists. American Journal of Clinical Nutrition 70, 532S-538S.

Gibson GR \& Roberfroid MB (1995) Dietary modulation of the human colonic microbiota, Introducing the concept of prebiotics. Journal of Nutrition 125, 1401-1412.

Goda T, Suruga K, Takase S, Ezawa I \& Hosoya N (1995) Dietary maltitol increases calcium content and breaking force of femoral bone in ovariectomized rats. Journal of Nutrition 125, 2869-2873.
Hämäläinen MM (1994) Bone repair in calcium-deficient rats, comparison of xylitol + calcium carbonate with calcium carbonate, calcium lactate and calcium citrate on the repletion of calcium. Journal of Nutrition 124, 874-881.

Hara H, Nagata M, Ohta A \& Kasai T (1996) Increases in calcium absorption with ingestion of soluble dietary fiber, guar-gum hydrolysate, depend on the caecum in partially nephrectomized and normal rats. British Journal of Nutrition 76, 773-784.

Hein A (1997) Der Einfluss unterschiedlicher Diäten auf die Struktur der Spongiosa von wachsenden und ovariektomierten Ratten. PhD Thesis, University of Kiel.

Heijnen AMP, Brink E, Lemmens AG \& Beynen AC (1993) Ileal $\mathrm{pH}$ and apparent absorption of magnesium in rats fed on diets containing either lactose or lactulose. British Journal of Nutrition 70, 747-756.

Kimmel DB (1996) Animal models for in vivo experimentation in osteoporosis research. In Osteoporosis, pp. 671-690 [R Marcus and D Feldman, editors]. San Diego: Academic Press.

Klein RF \& Carlos AS (1995) Inhibition of osteoblastic cell proliferation and ornithine decarboxylase activity by ethanol. Endocrinology 136, 3406-3411.

Le Blay G, Michel C, Blottière HM \& Cherbut C (1999) Prolonged intake of fructo-oligosaccharides induces a short-term elevation of lactic acid-producing bacteria and a persistent increase in cecal butyrate in rats. Journal of Nutrition 129, $2231-2235$.

Levrat M-A, Rémésy C \& Demigné C (1991) High propionic acid fermentations and mineral accumulation in the cecum of rats adapted to different levels of inulin. Journal of Nutrition 121, 1730-1737.

Löser C, Eisel A, Harms D \& Fölsch UR (1999) Dietary polyamines are essential luminal growth factors for small intestinal and colonic mucosal growth and development. Gut 44, 12-16.

Lopez HW, Coudray C, Levrat-Verny M, Feillet-Coudray C, Demigne C \& Remesy C (2000) Fructooligosaccharides enhance mineral apparent absorption and counteract the deleterious effects of phytic acid on mineral homeostasis in rats. Journal of Nutritional Biochemistry 11, 500-508.

Lupton JR \& Kurtz PP (1993) Relationship of colonic luminal short-chain fatty acids and $\mathrm{pH}$ to in vivo cell proliferation in rats. Journal of Nutrition 123, 1522-1530.

Mattila PT, Svanberg MJ, Pokka P \& Knuuttila ML (1998) Dietary xylitol protects against weakening of bone biomechanical properties in ovariectomized rats. Journal of Nutrition 128, 1811-1814.

Moshfegh AJ, Friday JE, Goldman JP \& Chug Ahuja JK (1999) Presence of inulin and oligofructose in the diets of Americans. Journal of Nutrition 129, 1407S-1411S.

Noack J, Kleessen B, Proll J, Dongowski G \& Blaut M (1998) Dietary guar gum and pectin stimulate intestinal microbial polyamine synthesis in rats. Journal of Nutrition 128, 1385-1391.

Noack J, Dongowski G, Hartmann L \& Blaut M (2000) The human gut bacteria Bacteroides thetaiotaomicron and Fusobacterium varium produce putrescine and spermidine in cecum of pectin-fed gnotobiotic rats. Journal of Nutrition 130, $1225-1231$.

Ohta A, Osakabe N, Yamada K, Saito Y \& Hidaka H (1993) Effects of fructooligosaccharides on $\mathrm{Ca}, \mathrm{Mg}$ and $\mathrm{P}$ absorption in rats. Japanese Society of Nutrition and Food Science 46, $123-129$.

Ohta A, Baba S, Takizawa T \& Adachi T (1994) Effects of fructooligosaccharides on the absorption of magnesium in the magnesium-deficient rat model. Journal of Nutritional Science and Vitaminology 40, 171-180.

Ohta A, Ohtsuki M, Baba S, Adachi T, Sakata T \& Sakaguchi EI (1995a) Calcium and magnesium absorption from the colon 
and rectum are increased in rats fed fructooligosaccharides. Journal of Nutrition 125, 2417-2424.

Ohta A, Ohtsuki M, Baba S, Takizawa T, Adachi T \& Kimura S (1995b) Effects of fructooligosaccharides on the absorption of iron, calcium and magnesium in iron-deficient anemic rats. Journal of Nutritional Science and Vitaminology 41, 281-291.

Ohta A, Ohtsuki M, Hosono A, Adachi T, Hara H \& Sakata T (1998a) Dietary fructooligosaccharides prevent osteopenia after gastrectomy in rats. Journal of Nutrition 128, 106-110.

Ohta A, Ohtsuki M, Uehara M, Hosono A, Hirayama M, Adachi T \& Hara H (1998b) Dietary fructooligosaccharides prevent postgastrectomy anemia and osteopenia in rats. Journal of Nutrition 128, 485-490.

Ohta A, Motohashi Y, Ohtsuki M, Hirayama M, Adachi T \& Sakuma K (1998c) Dietary fructooligosaccharides change the intestinal mucosal concentration of calbindin-D9k in rats. Journal of Nutrition 128, 934-939.

Rémésy C, Levrat M-A, Gamet L \& Demigné C (1993) Cecal fermentations in rats fed oligosaccharides (inulin) are modulated by dietary calcium level. American Journal of Physiology 264, G855-862.

Rowland IR \& Tanaka R (1993) The effects of transgalactosylated oligosaccharides on gut flora metabolism in rats associated with a human faecal microflora. Journal of Applied Bacteriology 74, 667-674.

Sako T, Matsumoto K \& Tanaka R (1999) Recent progress on research and application of non-digestible galacto-oligosaccharides. International Dairy Journal 9, 69-80.

Schneeman BO (1999) Fiber, inulin and oligofructose, similarities and differences. Journal of Nutrition 129, 1424S-1427S

Scholz-Ahrens KE, Hein A \& Bößmann K (1997) Quantification of bone structure as parameter of calcium bioavailability. In Bioavailability, Proceedings of the International Symposium on Bioavailability at the Agricultural University of Wageningen, p. 124.

Scholz-Ahrens KE, van Loo J \& Schrezenmeir J (1998)
Oligofructose stimuliert die Femurmineralisation in Abhängigkeit von der Calciumzufuhr bei der ovariektomierten Ratte. European Journal of Nutrition 37, 124.

Scholz-Ahrens KE, Schaafsma G, van den Heuvel EGHM \& Schrezenmeir J (2001) Effects of prebiotics on mineral metabolism. American Journal of Clinical Nutrition 73, 459S-464S.

Scholz-Ahrens KE, Açil Y \& Schrezenmeir J (2002) Effect of oligofructose or dietary calcium on repeated calcium and phosphorus balances, bone mineralization and trabecular structure in ovariectomized rats. Submitted to British Journal of Nutrition.

Schulz AG, Van Amelsvoort JM \& Beynen AC (1993) Dietary native resistant starch but not retrograded resistant starch raises magnesium and calcium absorption in rats. Journal of Nutrition 123, 1724-1731.

Straub BW, Kicherer M, Schilcher SM \& Hammes WP (1995) The formation of biogenic amines by fermentation organisms. Zeitschrift für Lebensmittel-Untersuchung und -Forschung 201, 79-82.

Takahara S, Morohashi T, Sano T, Ohta A, Yamada S \& Sasa R (2000) Fructooligosaccharide consumption enhances femoral bone volume and mineral concentrations in rats. Journal of Nutrition 130, 1792-1795.

Trinidad TP, Wolever TM \& Thompson LU (1996) Effect of acetate and propionate on calcium absorption from the rectum and distal colon of humans. American Journal of Nutrition 63, 574-578.

van Loo J, Cummings J, Delzenne N, Englyst H, Franck A, Hopkins M, Kok N, Macfarlane G, Newton D, Quigley M, Roberfroid M, van Vliet T \& van den Heuvel EGHM (1999) Functional food properties of NDO a consensus report from the 'Endo' project (DGXII AIRII-CT94-1095). British Journal of Nutrition 81, 121-132.

Wang X \& Gibson GR (1993) Effects of the in vitro fermentation of oligofructose and inulin by bacteria growing in the human large intestine. Journal of Applied Bacteriology 75, 373-380. 